\title{
An assessment of computer-assisted personalized sedation: a sedation delivery system to administer propofol for gastrointestinal endoscopy
}

Daniel J. Pambianco, MD, FACG, Christopher J. Whitten, MD, Annelies Moerman, MD, Michel M. Struys, MD, PhD, James F. Martin, PhD

Charlottesville, Virginia, Cincinnati, Ohio, USA, Gent, Belgium

Background: Demand for colonoscopy and EGD procedures is increasing. Impediments to performing these examinations persist. Patients perceive these procedures as unpleasant and painful. The use of suboptimal sedatives results in inefficiency in endoscopy practices. Improving sedation methods utilizing precise control of preferred sedatives may increase patient satisfaction and practice efficiency.

Objective: Our purpose was to demonstrate the feasibility of computer-assisted personalized sedation (CAPS) for facilitating the precise administration of propofol by endoscopist/nurse teams, achieving minimal to moderate sedation in subjects undergoing routine endoscopies.

Design: Open label, single-center studies.

Setting: Endoscopy clinics in Charlottesville, Virginia, and Gent, Belgium.

Subjects: Twenty-four adults per center; 12 colonoscopies, 12 EGDs.

Interventions: Propofol sedation with CAPS by endoscopist/registered nurse care teams.

Main Outcome Measurements: Sedation level measured by modified observer's assessment of alertness/sedation $(\mathrm{MOAA} / \mathrm{S})$, recovery time measured from endoscope removal until Aldrete $\geq 12$, dosage of propofol, oxygen saturation, and safety assessments.

Results: Subjects responded to mild tactile and verbal stimuli MOAA/S $=5,4,3$, or 2) $99 \%$ of the time. Mean propofol doses in the United States and Belgium were 65.4 and $72.1 \mathrm{mg}$, respectively. Mean recovery times were 29 and 10 seconds, respectively. Oxygen desaturation occurred in only $6 \%$ of subjects. No device-related adverse events occurred.

Limitation: Open-label design.

Conclusions: Using CAPS, the endoscopist/nurse teams precisely controlled the administration of propofol achieving minimal to moderate sedation in subjects undergoing colonoscopy and EGD procedures. Mean propofol dosage was low and post-procedure recovery times were rapid. The device performed well when operated by the endoscopist/nurse team, with no device-related adverse events.

Colorectal cancer is the third most common cancer diagnosed in the United States. The American Cancer Society estimated that in 2007 about 112,000 new cases of colon cancer and 41,000 new cases of rectal cancer would be detected and, that of these, about 52,000 individuals would

Abbreviations: ASA, American Society of Anesthesiologists; CAPS, computer-assisted personalized sedation; CSSI, clinician satisfaction with sedation instrument; MOAA/S, modified observer's assessment of alertness/sedation; NIBP, noninvasive blood pressure; PSSI, patient satisfaction with sedation instrument.

Copyright $\odot 2008$ by the American Society for Gastrointestinal Endoscopy 0016-5107/\$32.00

doi:10.1016/j.gie.2008.02.011 die of this disease. ${ }^{1}$ Despite these data, the perception that these procedures are unpleasant and painful dissuade many patients from having a colonoscopy. Further, practice inefficiency in endoscopy centers resulting from the use of suboptimal sedatives can result in significant wait times for those patients wishing to have the procedure.

In recent years, the number of routine endoscopy procedures performed has grown substantially, due to an aging population, increased subject awareness of the benefits of cancer screening, and revised reimbursement policies for colonoscopy. ${ }^{2,3}$ The demand for procedures has exceeded the ability of endoscopists to screen patients in a timely manner, and patient wait times of 3 to 6 months are not uncommon. ${ }^{4}$ Based on a National Health 
Interview Survey, it has been estimated that less than 30\% of adults aged 50 and older currently undergo routine colorectal screening by colonoscopy. ${ }^{5}$ The American Cancer Society has sought to increase these rates and has established the goal that $75 \%$ of eligible individuals be screened by the year $2015 .^{6}$ Thus, the demands for routine endoscopy procedures are expected to continue to increase.

One method of reducing these growing backlogs in screening is to improve the throughput at endoscopy centers via practice efficiency. ${ }^{7}$ Increased practice efficiency may be achieved by reducing the time patients spend in the recovery room by changing sedation practice. The current standard of care for sedation includes the administration of a combination of anxiolytic drugs, such as midazolam or diazepam, and analgesic drugs, usually fentanyl or meperidine. ${ }^{8,9}$ These drugs, however, are associated with nausea, suboptimal drug clearance, and long half-lives, resulting in increased time spent in the recovery room. ${ }^{7}$

In patients undergoing routine endoscopy procedures, the rapid action and short half-life of propofol offers an excellent sedative state and early recovery ${ }^{10,11}$ While it has guidelines for sedation by non-anesthesiologists, the American Society of Anesthesiologists (ASA), as well as the American Association of Nurse Anesthetists, recommends the administration of propofol only by individuals trained in general anesthesia. ${ }^{12}$ Due to the shortage of anesthesiologists and nurse anesthetists, however, it is clear that too few of these professionals are available to support propofol use in routine endoscopy procedures. ${ }^{13,14}$ Moreover, propofol administration by anesthesiologists is not cost effective for these procedures, and many third-party payers are eliminating payment for the services of anesthesia personnel. ${ }^{15}$

Computer-assisted personalized sedation (CAPS) is a novel approach to propofol sedation. It integrates a suite of patient monitors with computer-controlled propofol delivery to enable precise control of sedation. These feasibility studies illustrate the capability of CAPS for enabling an endoscopist/nurse team to administer propofol sedation during colonoscopy and EGD procedures.

\section{METHODS}

\section{Description of the CAPS device}

SEDASYS (Ethicon Endo-Surgery, Inc, Cincinnati, $\mathrm{OH}$ ) is an investigational CAPS device. It integrates the monitoring of pulse oximetry, capnometry, EKG, noninvasive blood pressure (NIBP), and patient responsiveness, with oxygen and propofol delivery. SEDASYS is compliant with relevant sections of the ASA guidelines on sedation/ analgesia by non-anesthesiologists ${ }^{16}$ and the dosing guidelines in propofol's package insert. It facilitates the titration of sedation to the desired clinical effect by automatically calculating and delivering a loading dose for every change

\section{Capsule Summary}

\section{What is already known on this topic}

- Propofol is the preferred sedative for procedural sedation, but it is approved for administration only by persons trained in the administration of general anesthesia.

\section{What this study adds to our knowledge}

- In 2 open-label, single-center studies, each with 24 subjects undergoing elective $\mathrm{Gl}$ endoscopy and colonoscopy, computer-assisted personalized sedation facilitated propofol administration by the endoscopistnurse team, achieving a level of sedation that was satisfactory to both clinicians and patients.

- Mean propofol dosage was low, recovery times were rapid, and no device-related adverse events occurred.

in propofol infusion rate, and its as-needed function enables supplemental doses of sedative to treat transient episodes of discomfort. SEDASYS incorporates restrictions in infusion rates and infusion rate increases tied to the subject's response to mild verbal and tactile stimuli. Additionally, it responds to early signs of oversedation, as indicated by apnea or hypoxemia, by stopping delivery of propofol and increasing oxygen delivery, as well as by prompting the subject to take a deep breath. Upon resumption of normal ventilatory function, it resumes the delivery of propofol at a reduced infusion rate, or recommends a reduced rate and requires the endoscopist/nurse team to resume delivery of sedative. SEDASYS cannot initiate an increase in infusion rate or any additional dosing of propofol at any time.

\section{Study design}

These were 2 open-label, single-center studies, at Charlottesville Medical Research, Charlottesville, Virginia, and at Ghent University Hospital, Gent, Belgium. Each center enrolled 24 adult ( $\geq 18$ years) subjects -12 for colonoscopy and 12 for EGD procedures. All subjects were ASA Class I, II, or III. Exclusion criteria included allergy or inability to tolerate study medications (including an allergy to eggs), a baseline oxygen saturation $<90 \%$ (on room air), women who were pregnant or nursing, or participation in a clinical trial within the previous 30 days. The study design was approved by the institutional review board/ethics committee of each institution and the Food and Drug Administration/Competent Authority of each country, and all subjects provided written informed consent.

Subjects for colonoscopy were given a colon-cleansing preparation the evening before the examination, and all subjects consumed nothing by mouth up to 4 hours before the study procedure. Subjects who were healthy 


\begin{tabular}{|c|c|c|}
\hline $\begin{array}{l}\text { TABLE } 1 . \\
\text { sedation }\end{array}$ & $\begin{array}{l}\text { Modified observer's assessn } \\
\text { (MOAA/S) }\end{array}$ & ment of alertness/ \\
\hline $\begin{array}{l}\text { MOAA/S } \\
\text { Score }\end{array}$ & Description & $\begin{array}{l}\text { ASA sedation } \\
\text { continuum }\end{array}$ \\
\hline 5 & $\begin{array}{l}\text { Responds readily to name } \\
\text { spoken in normal tone } \\
\text { (awake) }\end{array}$ & Minimal sedation \\
\hline 4 & $\begin{array}{l}\text { Lethargic response to } \\
\text { name spoken in } \\
\text { normal tone }\end{array}$ & Moderate sedation \\
\hline 3 & $\begin{array}{l}\text { Responds after name } \\
\text { called loudly or repeatedly }\end{array}$ & Moderate sedation \\
\hline 2 & $\begin{array}{l}\text { Purposeful response to } \\
\text { mild prodding or mild } \\
\text { shaking }\end{array}$ & Moderate sedation \\
\hline 1 & $\begin{array}{l}\text { Responds to trapezius } \\
\text { squeeze (includes purposeful } \\
\text { and reflexive withdrawal) }\end{array}$ & Deep sedation \\
\hline 0 & $\begin{array}{l}\text { No response to painful } \\
\text { stimulus (trapezius squeeze) }\end{array}$ & General anesthesia \\
\hline
\end{tabular}

and $<65$-years old were administered a single dose of 50 to $100 \mu \mathrm{g}$ fentanyl, whereas subjects who were frail, debilitated, and/or $\geq 65$-years old were administered a single dose of 25 to $50 \mu \mathrm{g}$ fentanyl. Three minutes later, propofol was initiated at $75 \mu \mathrm{g} / \mathrm{kg} /$ minute and then titrated to desired clinical effect, with infusion rate increases/decreases, and/or the use of an as-needed dose of $0.25 \mathrm{mg} / \mathrm{kg}$. Propofol infusion was stopped or reduced during withdrawal of the endoscope as determined by the anticipated length of the withdrawal.

The level of sedation was determined by a modified observer's assessment of alertness/sedation scores (MOAA/S) every 2 minutes (Table 1). Aldrete score was assessed every minute following removal of the endoscope, with recovery time measured as the time from endoscope removal to Aldrete $\geq 12$. All vital signs and propofol dosing were captured electronically. Psychomotor tests were performed at baseline, on attainment of Aldrete $\geq 12$, and after an additional 30 minutes. Clinician and subject satisfaction were assessed by 2 newly validated measures, the Clinician Satisfaction with Sedation Instrument (CSSI) and the Patient Satisfaction with Sedation Instrument (PSSI). ${ }^{17,18}$

Safety assessments included incidence and duration of desaturation $\left(\mathrm{SpO}_{2}<90 \%\right.$ for $>15$ seconds), incidence and duration of apnea (lack of ventilatory activity for $>30$ seconds), incidence of bradycardia (heart rate $<50 \mathrm{bpm}$ for $\geq 30$ seconds), incidence of hypotension (systolic blood pressure $<90 \mathrm{~mm} \mathrm{Hg}$ for 2 or more consecutive NIBP readings taken approximately 3 minutes apart). All decisions made by SEDASYS were evaluated by anesthesiologists following the procedures.

\begin{tabular}{|c|c|c|c|}
\hline TABLE 2. Subject $c$ & lemographic & & \\
\hline & $\begin{array}{c}\text { US } \\
\text { subjects }\end{array}$ & $\begin{array}{l}\text { Belgian } \\
\text { subjects }\end{array}$ & Total \\
\hline Colonoscopy/EGD & $12 / 12$ & $12 / 12$ & $24 / 24$ \\
\hline ASA Class I/II/III & $2 / 15 / 7$ & $11 / 9 / 4$ & $13 / 24 / 11$ \\
\hline Males/females & $11 / 13$ & $12 / 12$ & $23 / 25$ \\
\hline $\begin{array}{l}\text { Median age year } \\
\text { (range) }\end{array}$ & $54(31-70)$ & $53(21-73)$ & $54(21-73)$ \\
\hline $\begin{array}{l}\text { Median weight } \\
\text { kg (range) }\end{array}$ & $80(56-107)$ & $74(45-109)$ & 77 (45-109) \\
\hline $\begin{array}{l}\text { Median BMI kg/m² } \\
\text { (range) }\end{array}$ & $28(21-41)$ & $26(20-39)$ & $27(20-41)$ \\
\hline
\end{tabular}

Adverse events, concomitant medications, number of polyps identified, and concomitant procedures were recorded.

\section{Statistical methods}

Continuous safety and effectiveness parameters were summarized by presenting the number of subjects, mean, standard deviation, minimum, and maximum by procedure (EGD or colonoscopy), and by center (U.S. or Belgium). Tabulation of categorical parameters by procedure included counts and percentages. Propofol infusion rate was assessed for total procedure, intubation (from endoscope "in" to cecum/duodenum), and withdrawal (from cecum/duodenum to endoscope "out").

\section{RESULTS}

\section{Subject demographics}

The demographic characteristics of the United States and Belgian subjects are shown in Table 2. The 2 groups of subjects were sufficiently matched in age, gender, ASA classification, weight, and body mass index.

\section{Sedation level}

Subject alertness was assessed at 2-minute intervals by MOAA/S scoring. Figure 1 shows that at 99\% of the measures, subjects were responsive to mild tactile and/or verbal stimuli $(\mathrm{MOAA} / \mathrm{S}=5,4,3$, or 2$)$. In only $1 \%$ of measures did subjects require a trapezius squeeze to generate a response $(\mathrm{MOAA} / \mathrm{S}=1)$ and at no time was a subject nonresponsive to a trapezius squeeze $(\mathrm{MOAA} / \mathrm{S}=0)$.

It would be reasonable to assume that the intended level of sedation is equivalent to the mean MOAA/S score for each subject. Figure 2 represents the individual mean MOAA/S values for all 48 subjects included in the U.S. and Belgian centers. It is important to note that all subject values are on the left half of the MOAA/S graph, 


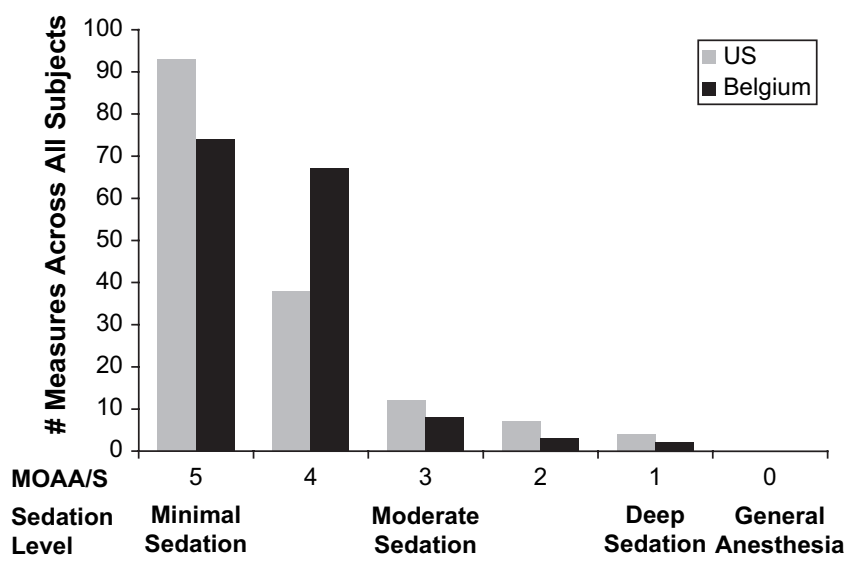

Figure 1. Individual MOAA/S scores for all 48 subjects.

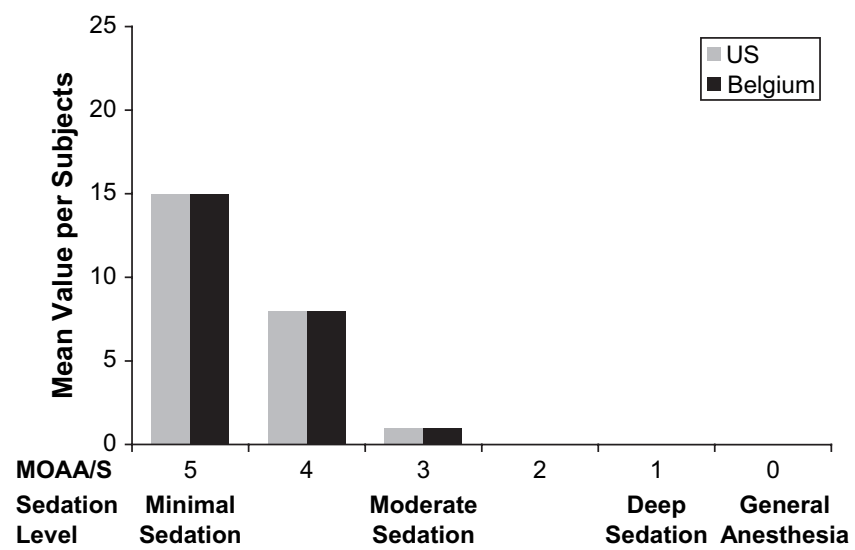

Figure 2. Mean MOAA/S scores for all 48 subjects.

TABLE 3. Propofol infusion rate summary

\begin{tabular}{lccccccc} 
& \multicolumn{2}{c}{ United States, mean* \pm SD (range) } & & \multicolumn{3}{c}{ Belgium, mean* \pm SD (range) } \\
\cline { 2 - 3 } & Colonoscopy & EGD & & Colonoscopy & EGD \\
\hline Procedure infusion rate $(\mu \mathrm{g} / \mathrm{kg} / \mathrm{min})$ & $55.4 \pm 8.8(42.7-70.2)$ & $51.2 \pm 17.6(3.9-66.4)$ & & $68.0 \pm 14.4(44.5-88.1)$ & $64.8 \pm 6.0(53.2-72.9)$ \\
Intubation infusion rate $(\mu \mathrm{g} / \mathrm{kg} / \mathrm{min})$ & $72.3 \pm 8.4(47.9-81.8)$ & $60.9 \pm 20.4(5.0-75.5)$ & $80.3 \pm 9.4(65.0-97.0)$ & $73.3 \pm 5.4(55.7-75.5)$ \\
Withdrawal infusion rate $(\mu \mathrm{g} / \mathrm{kg} / \mathrm{min})$ & $12.1 \pm 8.0(0.0-27.4)$ & $14.6 \pm 13.3(0.0-47.6)$ & & $29.8 \pm 27.7(0.0-90.9)$ & $41.9 \pm 17.3(14.3-72.9)$ \\
\hline
\end{tabular}

demonstrating that the endoscopist was targeting minimal to moderate sedation while using CAPS.

\section{Drug dosing}

For colonoscopy, the mean propofol dosage needed to achieve and maintain desired sedation levels was $82.7 \mathrm{mg}$ (range 50 - $110 \mathrm{mg}$ ) in the United States and $102.5 \mathrm{mg}$ (range 60 - $150 \mathrm{mg}$ ) in Belgium. For EGD, the mean propofol dosage was $49.2 \mathrm{mg}$ (range 20 - $80 \mathrm{mg}$ ) in the United States and $41.7 \mathrm{mg}$ (range 20 - $60 \mathrm{mg}$ ) in Belgium. The mean average propofol infusion rates for the procedure, intubation portion of the procedure, and withdrawal portion of the procedure are shown in Table 3 for both colonoscopy and EGD. The mean fentanyl dosage was $89 \mu \mathrm{g}$ (range $25-100 \mu \mathrm{g}$ ) in the United States and $67 \mu \mathrm{g}$ (range $25-100 \mu \mathrm{g})$ in Belgium.

\section{Recovery and procedure times}

The mean recovery times, from endoscope "out" to Aldrete $\geq 12$, in the United States and Belgium were 29 and 10 seconds, respectively, for colonoscopy, and 28 and 10 seconds, respectively, for EGD. The mean procedure times, from endoscope "in" to endoscope "out," in the United States and Belgium were 9 minutes 29 seconds (range 6:30 - 14:03) and 11 minutes 51 seconds (range 5:49 - 20:04), respectively, for colonoscopy, and 2 minutes
29 seconds (range 1:34 - 4:10) and 2 minutes 44 seconds (range 1:41 - 4:28), respectively, for EGD.

\section{Subjective assessments}

In the United States, 11 of 24 (46\%) subjects had little or no recall of the procedure, whereas 13 (54\%) had much or complete recall. In Belgium, 8 of 24 (33\%) subjects had little or no recall of the procedure, whereas 16 (67\%) had much or complete recall. In both United States and Belgian centers, the level of satisfaction with CAPS among both endoscopists and subjects was high (Table 4). Postprocedure assessments by the anesthesiologist at each study site agreed with all clinically significant decisions made by SEDASYS (over 21,000 device decisions).

\section{Safety assessments}

Oxygen desaturation occurred in only 3 of 48 (6\%) subjects; the mean duration of desaturation was 26 seconds in the United States (range 25 - 28 seconds) and 31 seconds in Belgium (range 16 - 45 seconds). Of the 48 subjects, 18 (38\%) experienced at least one episode of apnea $>30$ seconds; the mean time to recovery of respiration was 6 seconds (range 1 - 37 seconds) in the United States, and 6 seconds (range 2 - 30 seconds) in Belgium. No subjects experienced hypotension or bradycardia. There was no necessity for oral airways or other ventilatory support measures. There were no device- or drug-related adverse events. 


\begin{tabular}{|c|c|c|}
\hline & United States & Belgium \\
\hline Endoscopist satisfaction* mean $\pm S D$ & $99.4 \pm 1.5$ & $85.9 \pm 8.4$ \\
\hline Subject satisfaction $\dagger$ mean $\pm S D$ & $95.3 \pm 7.6$ & $90.4 \pm 10.0$ \\
\hline \multicolumn{3}{|c|}{$\begin{array}{l}\text { * Using the clinician satisfaction with sedation instrument }(\text { CSSI), in which } 0=\text { very dissatisfied and } 100= \\
\text { very satisfied. } \\
\text { †Using the patient satisfaction with sedation instrument (PSSI), in which } 0=\text { very dissatisfied and } 100= \\
\text { very satisfied. }\end{array}$} \\
\hline
\end{tabular}

\section{DISCUSSION}

CAPS is a novel approach to sedation that integrates continuous physiological monitoring with the delivery of propofol through a computer interface to facilitate precise control of level of sedation. SEDASYS, the CAPS device used in this study, is compliant with relevant sections of the ASA guidelines on sedation/analgesia by non-anesthesiologists ${ }^{16}$ and the dosing guidelines in propofol's package insert. Using SEDASYS, the endoscopist/nurse team precisely controlled the administration of propofol to achieve minimal to moderate sedation in subjects undergoing routine endoscopy procedures.

In this study, all 48 subjects undergoing colonoscopy or EGD procedures were moderately sedated, with mean subject MOAA/S scores of $3(n=2), 4(n=16)$, and $5(n=30)$. The endoscopist/nurse teams achieved the desired levels of sedation with substantially lower dosages of propofol than those reported with the nurse-administered propofol sedation (NAPS) trial. ${ }^{19}$ In both the U.S. and Belgian centers, the mean propofol dosages (65.5 and $72.1 \mathrm{mg}$, respectively) were about one third of the mean dosage reported in the NAPS study. The mean propofol infusion rates achieved with CAPS $(55.4 \mu \mathrm{g} / \mathrm{kg} / \mathrm{min}$ in United States and $66.4 \mu \mathrm{g} /$ $\mathrm{kg} / \mathrm{min}$ in Belgium) were well within the dosing guidelines in propofol's package insert ("most patients require an infusion of 25 to $75 \mu \mathrm{g} / \mathrm{kg} / \mathrm{min}$ ").

In addition, use of SEDASYS allowed for more precise control of the propofol infusion. For example, the mean average infusion rate for colonoscopy during withdrawal of the endoscope was less than $25 \%$ of the rate needed during intubation of the colon. This moment-to-moment control of propofol infusion led to very rapid $(<30 \mathrm{sec}-$ onds) postprocedure recovery from sedation. Validated physician and patient satisfaction with sedation scores showed that both endoscopists and subjects were highly satisfied with the level of sedation. Anecdotally, subjects who had had prior colonoscopy with opiates and benzodiazepines were highly satisfied with the rapid recovery, and in particular with the lack of sedation "hangover" normally expected to last several hours postprocedurally.

SEDASYS performed as designed, reducing or stopping propofol infusion at the first signs of oversedation. The in- cidence of oxygen desaturation was very low, with only $6 \%$ of subjects experiencing at least one event. In regard to apnea, it is likely that SEDASYS detects apnea more sensitively than clinical observation, suggesting that previously published assessments of apnea incidence in other studies may be too low. Thus, although $38 \%$ of subjects experienced at least one event, this incidence was probably comparable to those reported elsewhere. ${ }^{20}$ This was corroborated by postprocedure review by anesthesiologists who agreed with all clinically significant decisions made by the device. It is important to note that in this feasibility study, there was no necessity for oral airways or other ventilatory interventions, and there were no device-related adverse events.

In this study, the U.S. and Belgium data were comparable, thus demonstrating the reproducibility and consistency of the results obtained by the use of CAPS across 2 countries and 2 practice settings, viz, an outpatient private practice setting and an academic institution. The results reported here are also consistent with previous studies of propofol use, regarding subject comfort and satisfaction, quicker subject recovery, and less nausea and vomiting. ${ }^{10,21-29}$ These factors are important for improving practice efficiencies, permitting more procedures to be completed each day, and potentially increasing capacity to meet the rising demands for routine endoscopy procedures. ${ }^{29}$ In addition, a recent study conducted in a large community-based gastroenterology practice reported an increased rate of adenoma detection among physicians who had longer mean colonoscopy withdrawal times. ${ }^{30}$ Because recovery from propofol sedation is extremely rapid, the use of CAPS may allow endoscopists to be more thorough withdrawing the endoscope, without extending the length of the procedure. CAPS may improve both practice efficiency and quality of colonoscopy screening by reducing the time for patient recovery, albeit in the procedure or recovery rooms.

In conclusion, the findings reported here demonstrate the feasibility of CAPS to facilitate propofol sedation by endoscopist/nurse teams in subjects undergoing colonoscopy and EGD procedures. Further studies are needed with SEDASYS to fully establish the value of CAPS compared to the current sedation practice of benzodiazepines combined with opioids. 


\section{DISCLOSURE}

The following authors report that they have no disclosures relevant to this publication: C. J. Whitten, A. Moerman, M. M. Struys, J. F. Martin. The following author has disclosed an actual or potential conflict: D. J. Pambianco is a consultant for Ethicon Endo-Surgery, Inc. This study was sponsored by Etbicon Endo-Surgery, Inc, Cincinnati, Obio.

\section{REFERENCES}

1. American Cancer Society. Colorectal cancer: early detection. Available at: http://www.cancer.org/docroot/CRI/content/CRI_2_6X_Colorectal_ Cancer_Early_Detection_10.asp. Accessed October 19, 2007.

2. Prajapati DN, Saeian K, Binion DG, et al. Volume and yield of screening colonoscopy at a tertiary medical center after change in medicare reimbursement. Am J Gastroenterol 2003;98:194-9.

3. Seeff LC, Richards TB, Shapiro JA, et al. Is there endoscopic capacity to provide colorectal cancer screening to the unscreened population in the United States? Gastroenterology 2004;127:1661-9.

4. Scott G. Waits are common for colonoscopies. New York Times July 9, 2002. Available at: http://query.nytimes.com/gst/fullpage.html?res= 9CODEED91630F93AA35754C0A. Accessed April 29, 2008.

5. American Cancer Society. Colorectal cancer facts and figures - special edition 2005. Available at: http://www.cancer.org/docroot/STT/content/ ST__1x_Colorectal_Cancer_Facts_and_Figures_-_Special_Edition_2005. asp. Accessed December 15, 2006.

6. Sarfaty M. How to increase colorectal cancer screening rates in practice: a primary care clinician's evidence-based toolbox and guide. Available at: http://www.cancer.org/docroot/PRO/content/PRO_4_1x_ColonMD_ Clinicians_Manual.pdf.asp. Accessed December 15, 2006.

7. Lazzaroni M, Bianchi PG. Preparation, premedication and surveillance. Endoscopy 2003;35:103-11.

8. Keeffe EB, O'Connor KW. 1989 A/S/G/E survey of endoscopic sedation and monitoring practices. Gastrointest Endosc 1990;36:S13-8.

9. Vicari JJ. Sedation and analgesia. Gastrointest Endosc Clin North Am 2002;12:297-311, viii.

10. Vargo JJ, Zuccaro G Jr, Dumot JA, et al. Gastroenterologist-administered propofol versus meperidine and midazolam for advanced upper endoscopy: a prospective, randomized trial. Gastroenterology 2002;123:8-16.

11. American Gastroenterological Association. Gastroenterology societies reach consensus on recommendations for sedation during endoscopic procedures. Available at: http://www.gastro.org/wmspage.cfm?parm1 $=371$. Accessed November 14, 2006.

12. American Society of Anesthesiologists, American Association of Nurse Anesthetists. AANA-ASA joint statement regarding propofol administration. Available at: http://www.asahq.org/news/propofolstatement. htm. Accessed December 5, 2006.

13. Schubert A, Eckhout G, Cooperider T, et al. Evidence of a current and lasting national anesthesia personnel shortfall: scope and implications. Mayo Clin Proc 2001;76:995-1010.

14. Shortage of certified registered nurse anesthetists limits access to healthcare. Available at: http://www.anesthesiapatientsafety.com/na glance/shortage.asp. Accessed November 14, 2006.

15. Rex DK, Khalfan HK. Sedation and the technical performance of colonoscopy. Gastrointest Endosc Clin North Am 2005;15:661-72.
16. American Society of Anesthesiologists Task Force on Sedation and Analgesia by Non-Anesthesiologists. Practice guidelines for sedation and analgesia by non-anesthesiologists. Anesthesiology 2002;96:1004-17.

17. Revicki D, Vargo JJ, Howard K, et al. Development and validation of the Patient Satisfaction with Sedation Instrument (PSSI) [abstract]. Gastrointest Endosc 2006;63:AB145.

18. Vargo JJ, Howard K, Petrillo J, et al. Development and validation of the Clinician Satisfaction with Sedation Instrument (CSSI) [abstract]. Gastrointest Endosc 2006;63:AB145.

19. Walker JA, Mclntyre RD, Schleinitz PF, et al. Nurse-administered propofol sedation without anesthesia specialists in 9152 endoscopic cases in an ambulatory surgery center. Am J Gastroenterol 2003;98: 1744-50.

20. Vargo JJ, Zuccaro G Jr, Dumot JA, et al. Automated graphic assessment of respiratory activity is superior to pulse oximetry and visual assessment for the detection of early respiratory depression during therapeutic upper endoscopy. Gastrointest Endosc 2002;55 826-31.

21. Patterson KW, Casey PB, Murray JP, et al. Propofol sedation for outpatient upper gastrointestinal endoscopy: comparison with midazolam. Br J Anaesth 1991;67:108-11.

22. Carlsson U, Grattidge P. Sedation for upper gastrointestinal endoscopy: a comparative study of propofol and midazolam. Endoscopy 1995;27:240-3.

23. Wehrmann T, Kokabpick S, Lembcke B, et al. Efficacy and safety of intravenous propofol sedation during routine ERCP: a prospective, controlled study. Gastrointest Endosc 1999;49:677-83.

24. Vargo JJ, Zuccaro G Jr, Dumot JA, et al. Gastroenterologist-administered propofol for therapeutic upper endoscopy with graphic assessment of respiratory activity: a case series. Gastrointest Endosc 2000;52: 250-5.

25. Krugliak P, Ziff B, Rusabrov Y, et al. Propofol versus midazolam for conscious sedation guided by processed EEG during endoscopic retrograde cholangiopancreatography: a prospective, randomized, double-blind study. Endoscopy 2000;32:677-82.

26. Ng JM, Kong CF, Nyam D. Patient-controlled sedation with propofol for colonoscopy. Gastrointest Endosc 2001;54:8-13.

27. Sipe BW, Rex DK, Latinovich D, et al. Propofol versus midazolam/meperidine for outpatient colonoscopy: administration by nurses supervised by endoscopists. Gastrointest Endosc 2002;55:815-25.

28. Gasparovic S, Rustemovic N, Opacic M, et al. Comparison of colonoscopies performed under sedation with propofol or with midazolam or without sedation. Acta Med Austriaca 2003;30:13-6.

29. Rex DK, Overley CA, Walker J. Registered nurse-administered propofol sedation for upper endoscopy and colonoscopy: Why? When? How? Rev Gastroenterol Disord 2003;3:70-80.

30. Barclay RL, Vicari JJ, Doughty AS, et al. Colonoscopic withdrawal times and adenoma detection during screening colonoscopy. N Engl J Med 2006;355:2533-41.

Received November 12, 2007. Accepted February 4, 2008.

Current affiliations: Charlottesville Medical Research, Charlottesville (D.J.P., C.J.W.), Virginia, Ethicon Endo-Surgery Inc. (J.F.M.), Cincinnati, Ohio, USA; Department of Anesthesiology, Ghent University Hospital (A.M., M.M.S.), Gent, Belgium.

Reprint requests: Daniel J. Pambianco, MD, Medical Director, Charlottesville Medical Research 1340 Stony Point Road, Suite 102, Charlottesville, VA 22911. 